\title{
Evaluation of a rapid protein analyzer for determination of protein in milk and cream
}

\author{
J. K. Amamcharla and L. E. Metzger ${ }^{1}$ \\ Midwest Dairy Foods Research Center, Dairy Science Department, South Dakota State University, Brookings 57007-0647
}

\begin{abstract}
Accurate and rapid measurement of the protein content of milk is important from both a product quality and an economic standpoint. The Sprint rapid protein analyzer (CEM Corporation, Matthews, NC) is a commercial system based on a dye-binding technique and can be used for rapid measurement of protein in foods. The objective of the present study was to compare the Sprint method with the reference method (Kjeldahl method). Milk and cream samples were analyzed in duplicate for true protein and crude protein $(\mathrm{CP})$ using the reference method as well as the rapid method. Method comparison statistics (regression analysis, graphical representation, standard deviation of residuals, repeatability, and so on) were used to evaluate the agreement between the 2 methods. Regression coefficients and the intercepts were not significantly different from 1 and zero for $\mathrm{CP}$ measurement in milk and cream, respectively. The average coefficient of variance between the duplicate CP measurements for the Sprint method was found to be $0.40,0.49$, and 0.76 for milk, light cream, and heavy cream, respectively. True protein measurement in milk and cream also followed a similar trend. Overall, there exists a sufficient level of agreement between the Sprint rapid protein analyzer and Kjeldahl method for true protein and CP measurement of milk and cream samples.
\end{abstract}

Key words: dye-binding method, rapid protein analyzer, method comparison statistics

\section{INTRODUCTION}

Rapid and accurate analysis of the protein content of milk and other dairy products has numerous economic and technological consequences. Moreover, the protein content of milk has an important role in payment of milk as well as in determining the breeding value of cows (Buffler, 2008). The protein content of milk and milk

Received November 30, 2009.

Accepted April 7, 2010.

${ }^{1}$ Corresponding author: Lloyd.Metzger@sdstate.edu products can be measured using established techniques (Dumas and Kjeldahl methods). The Kjeldahl method was first introduced in the 1880s and is still widely used. Irrespective of some negative factors such as hazardous reagents, long analysis times (Simonne et al., 1997), and discrepancies in the conversion factor (O'Sullivan et al., 1999), it is internationally recognized as the reference method for measurement of the protein content of milk and milk products. In this method, the sample is digested in the presence of concentrated sulfuric acid with potassium sulfate and copper (II) sulfate serving as a catalyst. Digestion converts organic nitrogen present in the sample to ammonium sulfate in the digest. Ammonia is then liberated by adding an excess amount of sodium hydroxide. Ammonia is distilled into a boric acid solution and titrated with a known concentration of hydrochloric acid. The total nitrogen is then calculated from the ammonia. Barbano and Lynch (2006) recently described the advancements in milk component testing in the past $25 \mathrm{yr}$, which included improvements in protein testing using the Kjeldahl method. Earlier, the same group also reported the general principle, system optimization, and factors that contribute to erroneous results along with the possible solutions encountered when measuring the protein content using the Kjeldahl method (Lynch and Barbano, 1999).

Another well-established method used to measure the protein content of food products is based on combustion. This method is referred to as the Dumas method and was introduced in 1831. The principle of the method is to convert nitrogen present in the sample into gaseous $\mathrm{NO}_{\mathrm{x}}$ and $\mathrm{N}_{2}$ by complete combustion in a furnace maintained at 950 to $1,050^{\circ} \mathrm{C}$. The final product $\left(\mathrm{NO}_{\mathrm{x}}\right)$ is then reduced to $\mathrm{N}_{2}$ and measured using suitable techniques such as thermal conductivity, gas chromatography, and chemiluminescence. With the advancement of technology and availability of automated instruments, the combustion method has several advantages over the Kjeldahl method including ease of operation, operator safety, reduced time of analysis, and low cost per analysis (Owusu-Apenten, 2002). Wiles et al. (1998) compared the Kjeldahl and 
Dumas methods for routine analysis of proteins in an interlaboratory study. Eleven laboratories participated in the study and samples of milk, skim milk powder, and so on were evaluated. They reported that for milk the repeatability and reproducibility standard deviations $\left(\mathbf{R S D}_{\mathrm{r}}\right.$ and $\mathbf{R S D}_{\mathbf{R}}$, respectively) were 0.65 and $1.9 \%$ for the Kjeldahl method, respectively. However, these $\mathrm{RSD}_{\mathrm{r}}$ and $\mathrm{RSD}_{\mathrm{R}}$ values are significantly greater than those reported in another similar study (Barbano et al., 1990). In contrast to the Kjeldahl method, the Dumas method produced less than half the corresponding $\mathrm{RSD}_{\mathrm{r}}$ and $\mathrm{RSD}_{\mathrm{R}}$ for the samples with $>2 \mathrm{~g}$ of $\mathrm{N} / 100$ g. However, in case of milk samples $(<2 \mathrm{~g}$ of $\mathrm{N} / 100 \mathrm{~g})$, the $\operatorname{RSD}_{\mathrm{r}}(2 \%)$ and $\mathrm{RSD}_{\mathrm{R}}(7.3 \%)$ were higher than that of the Kjeldahl method. The lower repeatability and reproducibility of the Dumas method for milk samples could be attributed to the configuration of the instrument (configured for solid samples). In another study, comparing the Kjeldahl and Dumas methods, Simonne et al. (1997) concluded that the Dumas method could be used to replace the Kjeldahl method for dairy products without applying any correction factor.

In the 1950s, dye-binding techniques and infrared techniques were developed for rapid and accurate determination of food proteins (Grappin and RibadeauDumas, 1992). Over time, the dye-binding methods were widely replaced by infrared spectroscopy (Van Reusel and Klijn, 1987), probably because of improved on-line instrumentation and automation of infrared spectrophotometers that facilitate rapid measurement. Infrared spectrophotometry measures the absorption or transmission properties of a sample in the infrared region of the electromagnetic spectrum. The infrared technique is based on the absorbance of incident electromagnetic energy by certain structural groups present in a milk sample. Three carbonyl groups $(\mathrm{C}=\mathrm{O})$ and carbon-hydrogen groups $\left(\mathrm{CH}_{2}\right)$ of triglycerides present in fat, amide groups in protein, and hydroxyl groups in lactose are used for measurement of the fat, protein, and lactose content of milk samples (Posudin, 2007). The value of infrared analysis is dependent on the characteristics of the calibration sample set and on the accuracy of the reference values (typically determined with the Kjeldahl method; Barbano and Lynch, 2006). It is not cost effective for individual milk plant laboratories to maintain the calibration sample set along with accurate reference data. Consequently, individual milk plants typically procure well-planned calibration sets from commercial centralized laboratories to minimize the cost.

Dye-binding methods for protein analysis are based on excess addition of a dye (e.g., Amido black, Orange 12 , Orange $\mathrm{G}$ ) to the food sample. The dye contains acidic $-\mathrm{SO}_{3}$ groups that bind to basic sites of the AA histidine, arginine, and lysine. An acidic dye with a $\mathrm{pH}$ less than the isoelectic point of the protein causes the formation of an insoluble dye-protein complex (Ashworth et al., 1960). The precipitate is then removed by centrifugation or simple filtration. Consequently, the optical properties (intensity, absorbance, and so on) of the dye are reduced in the supernatant, which is then measured using a simple spectrophotometer. The degree of change in optical properties of the dye can then be correlated to the protein content of the sample. The dye-binding capacity of a protein is dependent on the accessibility of the dye to histidine, arginine, and lysine AA. Consequently, alterations in protein structure caused by processing can influence the dye-binding capacity of a protein (Sherbon, 1978). This method has been used for dairy products (Ashworth et al., 1960; Ashworth, 1965, 1966), potato products (Kaldy et al., 1972; Wu and Lakin, 1993), cereals (Biston and Clamot, 1982), and meat products (Ashworth, 1971; Riquelme and Ashworth, 1973). Several semiautomated and automated instruments that used dye binding were available in the past, but Udy (Udy Corporation, Fort Collins, CO) was the only product on market until CEM Corporation (Matthews, NC) recently launched an automated Sprint rapid protein analyzer. According to CEM Corporation, their proprietary iTag solution (dye) used by the Sprint rapid protein analyzer chemically binds to certain AA (histidine, arginine, and lysine) in the protein chain. The iTag solution contains 2 distinct parts, an aromatic portion and an acid group. The aromatic portion exhibits strong characteristic absorbance in visible region and appears orange in color. The acid group is responsible for binding to the AA in the protein macromolecule. The basic principle of the method is similar to other dye-binding methods. However, CEM Corporation combined all the processes in the method (sample weighing, predetermined dye addition, homogenization, filtration, and absorbance measurement) into a compact, sophisticated, and automated unit. The Sprint unit also uses a temperature probe to monitor the sample/iTag mixture and compensates the protein measurement for temperature. The unit has several advantages because it is rapid and easy to use. The unit complies with AOAC official methods 967.12, 930.33, and 930.29 (AOAC, 2000). The manufacturer also claims that the iTag solution is nonhazardous.

Because the Sprint method has potential applications for dairy products, it is important to evaluate the performance of this method relative to a well-established reference method like Kjeldahl. The objective of the current research was to evaluate the performance of the Sprint rapid protein analyzer and to evaluate the 
agreement between the rapid method and the reference method (Kjeldahl method).

\section{MATERIALS AND METHODS}

\section{Experimental Design}

The experimental plan was designed to evaluate the agreement between the rapid method and the reference method. Milk, light cream, and heavy cream samples were analyzed in duplicate using the reference method as well as the Sprint rapid protein analyzer. The CP and true protein (TP) contents of each sample were determined independently using the Sprint rapid method and then compared with the reference method results using linear regression and Deming regression.

\section{Test Samples}

Thirteen milks (pasteurized and homogenized), 10 light creams (unhomogenized), and 10 heavy creams (unhomogenized) were procured from DQCI Services (Mounds View, MN). All samples contained bronopol as an added preservative. DQCI Services is a certified laboratory under the National Conference of Interstate Milk Shippers (Monticello, IL). Samples are exclusively designed for calibration of laboratory instruments.

The following chemical methods were used as the reference methods for fat, TP, and CP: fat by modified Mojonnier (method 989.05; AOAC, 2000), and TP and CP by Kjeldahl analysis (method 991.20; AOAC, 2000). All the samples were analyzed in duplicate using the reference methods. Fat content of the samples ranged from 0.07 to $3.52 \%, 9.23$ to $18.77 \%$, and 30.53 to $44.78 \%$, respectively, for the milk, light cream, and heavy cream.

\section{Sprint Rapid Protein Analyzer}

A Sprint protein analyzer (CEM Corp., Matthews, NC) was used for analysis of the milk, light cream, and heavy cream samples. The calibration equations were developed for 2.04 to $4.26 \% \mathrm{CP}$ and 2.25 to $4.42 \%$ TP. The calibration equations are proprietary and were provided by CEM Corporation.

The standard measurement protocol was followed as described in the user manual (CEM Corporation, 2008). The entire analysis was automated and the only operator requirement was to add the sample to the sample cup. Operator influences were minimized by using a similar sample size $(2.2-2.3 \mathrm{~g})$ for all analyses and adding the sample to the bottom of the sample cup. Additionally, the homogenizer was cleaned periodically (after every fifth sample) and the iTag dye solution was prepared by strictly following the manufactures recommendations. The TP and CP of the milk, light cream, and heavy cream were measured in duplicate using the Tru Pro Milk and Crude Pro Crnll calibration equations provided by the manufacturer, respectively. A dedicated electronic weighing balance (Mettler-Toledo Inc., Columbus, $\mathrm{OH}$ ) was connected to the Sprint rapid protein analyzer via a serial port.

\section{Method Comparison Statistics}

The TP and CP of the samples obtained from the reference method $\left(\mathbf{R}_{\mathbf{f}}\right)$ and the rapid method $(\mathbf{R})$ were tabulated and compared using method comparison statistics including graphical and regression analysis. In graphical analysis, scatter plots and difference plots were used. Additionally, 2 regression-based methods (ordinary linear regression and Deming regression) were used to evaluate the agreement between rapid method and reference method.

Graphical Analysis. The difference plots were prepared by comparing the difference between the 2 methods $\left(R_{f}-R\right)$ against the mean of the 2 methods $\left[\left(R_{f}+R\right) / 2\right]$. A 95\% confidence interval for the mean difference was also calculated and plotted in the same difference plot to evaluate the extent of bias and to identify outliers. The scatter plots were developed between the reference method and the rapid method. A line of equality, or identity line (passing through origin with a slope of 1), and least squares regression line were also displayed in the same graph. Both the scatter plots and difference plots were developed using Microsoft Excel spreadsheet application package (Microsoft Corp., Redmond, WA). Further discussion on plotting of method comparison data can be found in Bland and Altman (1986) and Twomey (2006).

Spearman Rank Order Correlation Coefficient. The Spearman rank order correlation coefficient ( $\rho)$ was used to detect any monotonic trend present between the bias and mean value of the rapid and reference methods. The $\rho$ was also used to detect influence of fat content of the milk and cream samples on the bias. The $\rho$ was calculated using Microsoft Excel (Microsoft Corp.).

Ordinary Linear Regression and Deming Regression. Regression analysis was performed by considering the reference method and rapid method as independent and dependent variables, respectively. In ordinary linear regression (OLR), a regression line was calculated by minimizing the sum of residual squares in 1 direction only (i.e., in y-direction). In Deming regression (DR), the line was calculated by minimizing the distances of the dependent and independent variables orthogonal to the regression line. More discussion and 
Table 1. Crude protein (\%) of milk determined using the reference method and the rapid method along with their coefficients of variance

\begin{tabular}{|c|c|c|c|c|c|c|c|c|c|}
\hline Sample no. & Fat $(\%)$ & \multicolumn{4}{|c|}{ Reference method (Kjeldahl) } & \multicolumn{4}{|c|}{ Rapid method (Sprint) } \\
\hline 1 & 0.07 & 3.42 & 3.44 & 3.43 & 0.41 & 3.48 & 3.46 & 3.47 & 0.41 \\
\hline 3 & 0.48 & 3.36 & 3.38 & 3.37 & 0.42 & 3.40 & 3.41 & 3.41 & 0.21 \\
\hline 4 & 0.72 & 3.34 & 3.36 & 3.35 & 0.42 & 3.38 & 3.39 & 3.39 & 0.21 \\
\hline 5 & 0.82 & 3.33 & 3.34 & 3.34 & 0.21 & 3.33 & 3.35 & 3.34 & 0.42 \\
\hline 8 & 2.47 & 3.27 & 3.28 & 3.28 & 0.22 & 3.26 & 3.32 & 3.29 & 1.29 \\
\hline 9 & 3.21 & 3.26 & 3.29 & 3.28 & 0.65 & 3.25 & 3.28 & 3.27 & 0.65 \\
\hline 10 & 3.52 & 3.24 & 3.24 & 3.24 & 0.00 & 3.24 & 3.25 & 3.25 & 0.22 \\
\hline 11 & 0.08 & 3.50 & 3.52 & 3.51 & 0.40 & 3.54 & 3.51 & 3.53 & 0.60 \\
\hline 12 & 2.03 & 3.73 & 3.73 & 3.73 & 0.00 & 3.73 & 3.73 & 3.73 & 0.00 \\
\hline 13 & 3.48 & 3.38 & 3.39 & 3.39 & 0.21 & 3.41 & 3.39 & 3.40 & 0.42 \\
\hline
\end{tabular}

applications on DR can be found in various publications (Linnet, 1993; Martin, 2000). The slope and intercept and and their confidence intervals were calculated using Microsoft Excel (Microsoft Corp.) and MultiQC (version 6.0.4.3; Medical Laboratory Quality Control Software, Metz, France).

\section{RESULTS AND DISCUSSION}

\section{CP Content in Milk, Light Cream, and Heavy Cream}

The CP contents of milk, light cream, and heavy cream measured in duplicate using the reference method and the rapid method are shown in Tables 1, 2, and 3 , respectively. As shown in Table 1, the fat content of milk samples varied between 0.07 and $3.52 \%$, covering the normally occurring fat content in milk samples. The repeatability of the rapid method was evaluated in terms of coefficient of variability $(\mathbf{H C V})$ calculated from the duplicate measurements on the same sample under the same conditions. The coefficient of variance for milk samples was found to be between 0 and $0.65 \%$ and 0 and $1.29 \%$ for the reference method and the rapid method, respectively. The fat content of the light cream and heavy cream samples was between 9.2 and $18.8 \%$ and 30.5 and $44.8 \%$, respectively, and is shown in Tables 2 and 3, respectively. The \%CV for the heavy cream samples was slightly higher than for the light cream samples for both the reference method and the rapid method. A maximum average $\% \mathrm{CV}$ of $0.76 \%$ was observed for the heavy creams. The higher $\% \mathrm{CV}$ of the heavy cream samples may be a result of the higher viscosity of heavy cream, which may contribute to sampling error. In these experiments, repeatability evaluated in terms of \% CV for the rapid method was slightly higher relative to the reference method. However, repeatabil- ity of the reference method (\% CV of $0.2 \%$ for milk) was lower than that of other reported values. Hooi et al. (2004) reported a repeatability value of $0.385 \%$ for raw milk analyzed using the reference method. However, Lynch and Barbano (1999) suggested a difference between duplicate determinations should be $\leq 0.038 \%$ protein for milk samples analyzed using the Kjeldahl nitrogen (reference method). The reference method in the current research produced a maximum difference between duplicates of $0.03 \% \mathrm{CP}$, and the mean absolute difference between the replications calculated over 13 samples was found to be $0.012 \%$. The Sprint method also produced similar results compared with the reference method, with a mean absolute difference between the replications of $0.019 \%$ and a maximum difference between the duplicates of $0.06 \%$. The observed mean difference $(0.005 \%)$ and the standard deviation of difference $(0.024 \%)$ between the replicates for the rapid method were found to be well within the requirements of AOAC (O'Sullivan et al., 1999).

The plot between the differences in the $\mathrm{CP}$ of the milk samples measured by the reference and rapid methods against their mean value is shown in Figure 1a. All the differences were between the $95 \%$ confidence intervals of their mean, visually indicating a good agreement between the 2 methods. Similar relationships were found with the CP measured by the rapid and reference methods in light and heavy creams (Figures 1b and 1c). Only 1 light cream sample was found to fall beyond the 95\% upper confidence interval line as shown in Figure 1b. The CP of that particular sample was 2.80 and $2.77 \%$ as measured by the reference method and the rapid method, respectively (a bias of $0.03 \%$ between the 2 methods). The difference plot was also used to identify any relationship between the discrepancies in the reference method and the rapid method. For this 
Table 2. Crude protein (\%) of light cream determined using the reference method and the rapid method along with their coefficients of variance

\begin{tabular}{|c|c|c|c|c|c|c|c|c|c|}
\hline \multirow[b]{2}{*}{ Sample no. } & \multirow[b]{2}{*}{ Fat $(\%)$} & \multicolumn{4}{|c|}{ Reference method (Kjeldahl) } & \multicolumn{4}{|c|}{ Rapid method (Sprint) } \\
\hline & & Replicate 1 & Replicate 2 & Mean & $\% \mathrm{CV}$ & Replicate 1 & Replicate 2 & Mean & $\% \mathrm{CV}$ \\
\hline 3 & 10.98 & 3.01 & 3.03 & 3.02 & 0.47 & 3.04 & 3.03 & 3.04 & 0.23 \\
\hline 4 & 11.83 & 3.00 & 3.01 & 3.01 & 0.24 & 3.01 & 3.00 & 3.01 & 0.24 \\
\hline 5 & 13.35 & 2.94 & 2.96 & 2.95 & 0.48 & 2.97 & 2.94 & 2.96 & 0.72 \\
\hline 8 & 17.01 & 2.80 & 2.83 & 2.82 & 0.75 & 2.83 & 2.8 & 2.82 & 0.75 \\
\hline 9 & 18.03 & 2.79 & 2.80 & 2.80 & 0.25 & 2.78 & 2.76 & 2.77 & 0.51 \\
\hline 10 & 18.77 & 2.73 & 2.75 & 2.74 & 0.52 & 2.75 & 2.74 & 2.75 & 0.26 \\
\hline Average & & & & & 0.44 & & & & 0.49 \\
\hline
\end{tabular}

purpose, the $\rho$ was calculated between the difference of reference and rapid method (bias) versus their mean value and was found to be $-0.25,-0.5$, and -0.33 for milk, light cream, and heavy cream, respectively. The insignificant $(P>0.1) \rho$ indicates that there exists no correlation and the bias was random. Another interesting observation that can be made from these plots (Figures 1a, b, and c) is that the rapid method, when compared with the reference method, slightly overestimated the $\mathrm{CP}$ in milk, light cream, and heavy cream. The mean difference between the reference method and rapid method was found to be $-0.02,-0.015$, and $-0.013 \%$ for the milk, light cream, and heavy cream samples, respectively.

The scatter plots between the CP of milk, light cream, and heavy cream measured using the reference method and the rapid method are shown in Figures 2a, $\mathrm{b}$, and c. A simple linear regression line as well as the line of equality $(\mathrm{Y}=\mathrm{X})$ are also shown in Figures 2a, $\mathrm{b}$, and c. A visual interpretation can be drawn from Figures $2 \mathrm{a}, \mathrm{b}$, and $\mathrm{c}$ that a visual agreement exists be- tween the 2 methods. Method comparison statistics for determination of $\mathrm{CP}$ in milk, light cream, and heavy cream are provided in Table 4. Intercepts of OLR equations were $0.07,-0.21$, and -0.07 for milk, light cream, and heavy cream, respectively, and were not significantly $(P>0.05)$ different from zero. Similarly, the regression coefficients or slopes of OLR were 0.99, 1.04, and 1.08 for milk, light cream, and heavy cream, respectively. The slopes were also not significantly $(P$ $>0.05$ ) different from 1 . The "not significantly different zero intercepts" and "not significantly different slopes from 1" indicate an insignificant constant bias and insignificant proportional bias between the reference method and rapid method. The standard deviation of residuals $\left(\mathbf{S}_{\mathbf{y}, \mathbf{x}}\right)$ calculated from the OLR line was 0.016 for milk and 0.017 for the light cream and heavy cream. The $S_{y, x}$ represents the random error present between the 2 methods. Grappin and Ribadeau-Dumas (1992) described $S_{y, x}$ as a measure of accuracy of the rapid method. He also mentioned that the rapid method can be used to measure the protein content if the $\mathrm{S}_{\mathrm{y}, \mathrm{x}}$ var-

Table 3. Crude protein (\%) of heavy cream determined using the reference method and the rapid method along with their coefficients of variance

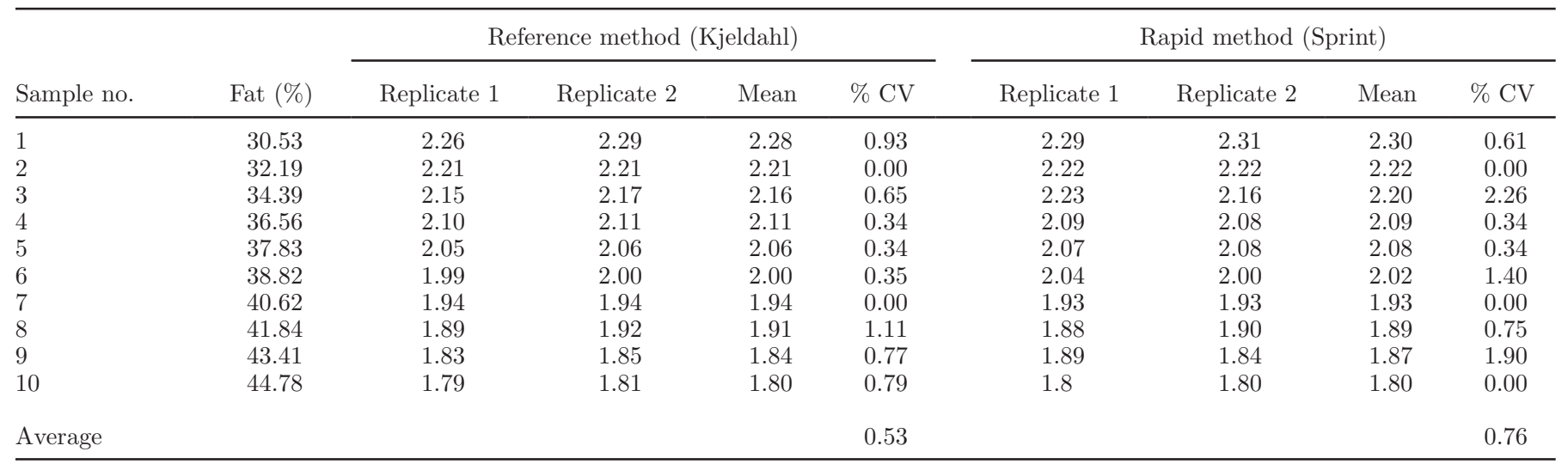


(a)

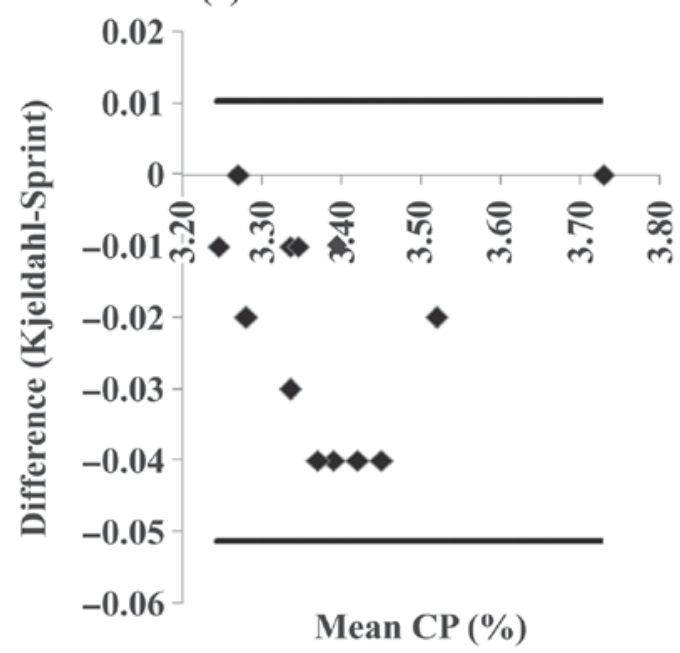

(b)

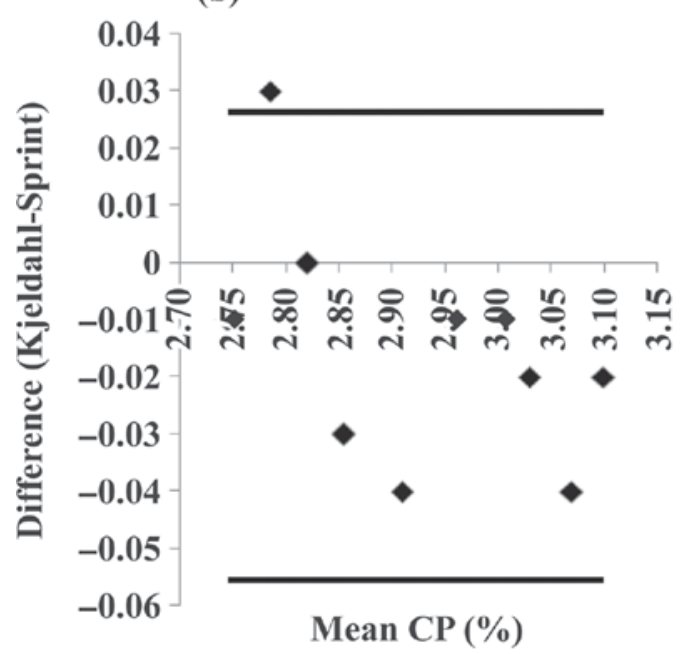

(c)

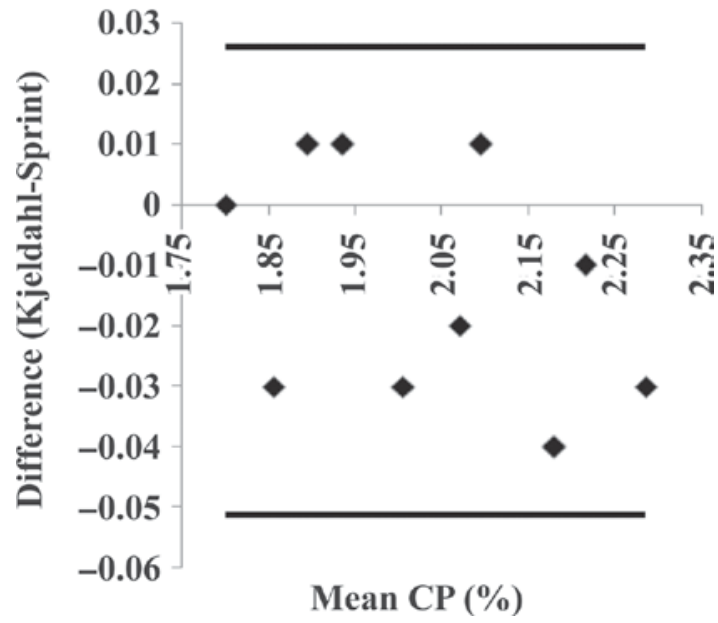

Figure 1. Plot showing the difference between the 2 methods against the mean $\mathrm{CP}$ (solid line indicates mean $\pm 1.96 \mathrm{SD}$ ) for a) milk, b) light cream, and c) heavy cream. (a)

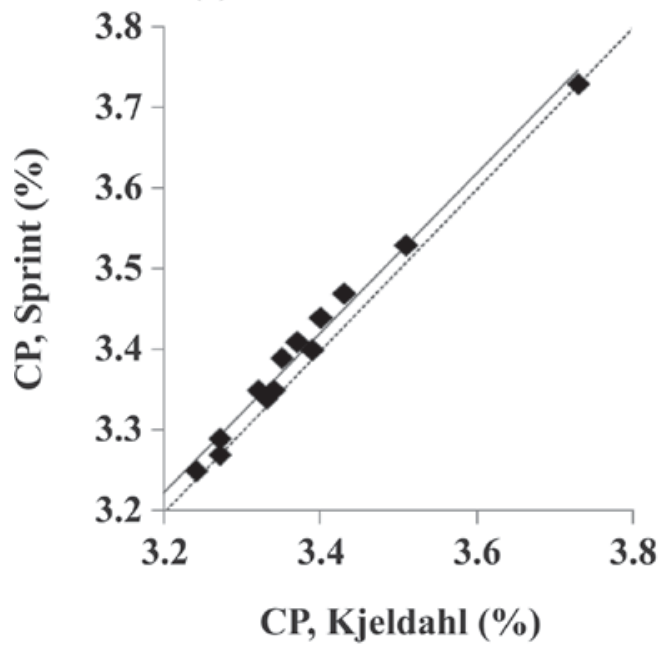

(b)
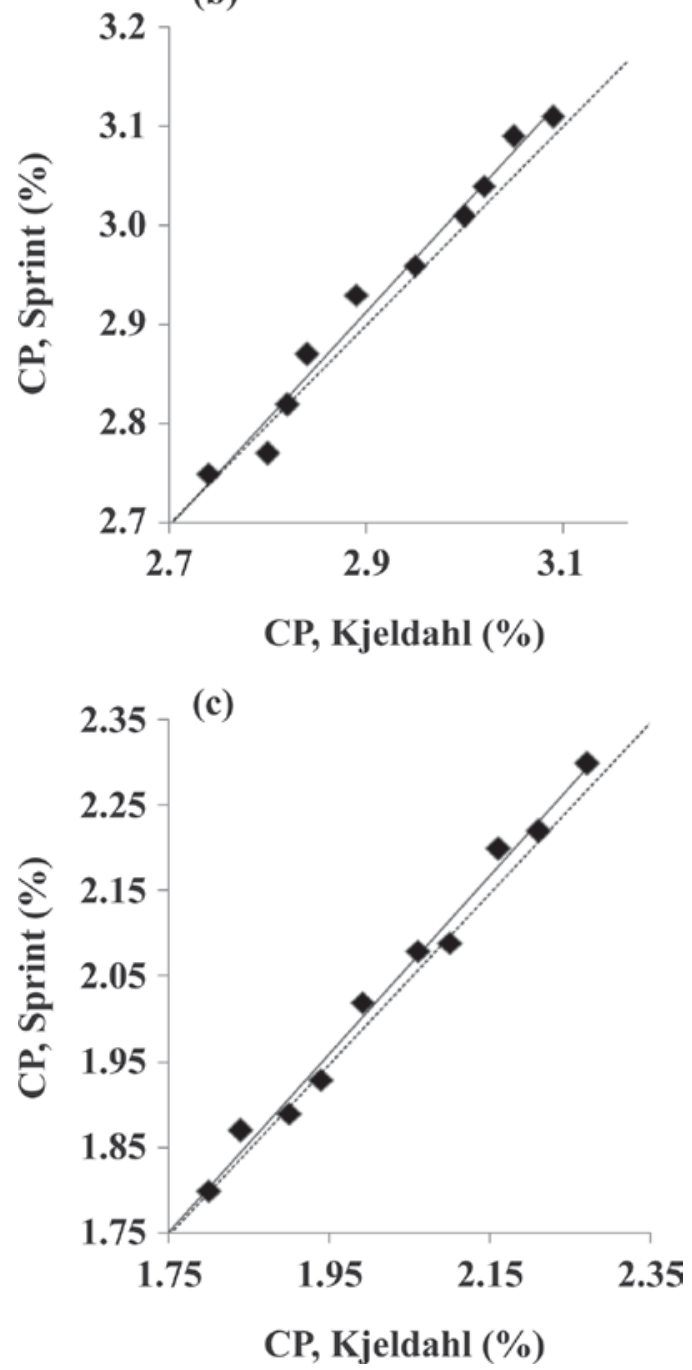

Figure 2. Crude protein content measured by the Kjeldahl and Sprint methods along with line of equality (dotted line; $\mathrm{Y}=\mathrm{X}$ ) for a) milk, b) light cream, and c) heavy cream. 
Table 4. Method comparison statistics for determination of CP in the milk, heavy cream, and light cream

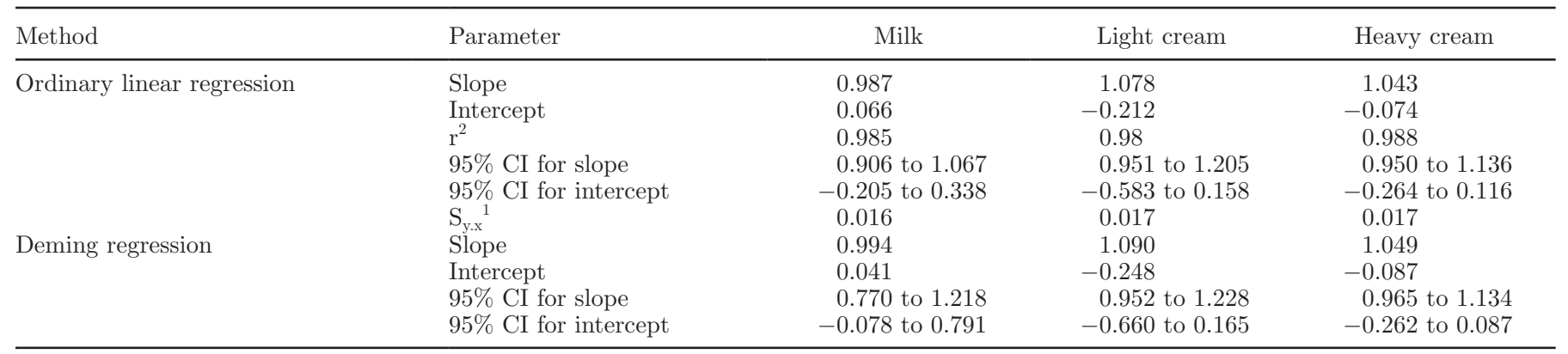

${ }^{1}$ Standard deviation of residuals.

ies between 0.03 and $0.06 \mathrm{~g} / 100 \mathrm{~g}$, depending on the origin of milk samples and method used (manual or automatic). Because the Sprint rapid protein analyzer is an automatic instrument and the test samples were from a commingled source, it is a safe estimate if the $\mathrm{S}_{\mathrm{y}, \mathrm{x}}$ is less than $0.06 \%$. In this study, the $\mathrm{S}_{\mathrm{y}, \mathrm{x}}$ for milk, light cream, and heavy cream was always less than $0.02 \%$. Consequently, this also indicates an agreement between the rapid method and reference method for $\mathrm{CP}$ analysis of milk and cream samples. The regression coefficients, intercept, correlation coefficient, and \%CV together strengthen the argument that the $\mathrm{CP}$ content in milk, light cream, and heavy cream measured using the rapid method was in agreement with that of the reference method.

\section{TP Content in Milk, Light Cream, and Heavy Cream}

The TP content of milk, light cream, and heavy cream measured using the reference method and the rapid method are shown in Tables 5, 6, and 7, respectively. The $\% \mathrm{CV}$ varied between 0 and $0.7 \%$ for the refer- ence method and 0 and $1.82 \%$ for the Sprint method using the milk samples (Table 5). The Sprint method produced a moderately high \% CV for the light cream (0.26-0.98\%) compared with the reference method $\% \mathrm{CV}(0-0.53 \%)$. Similar results were found with the heavy cream samples, which had a \%CV of 0 to $3.2 \%$ for the Sprint method compared with 0 to $2.35 \%$ for the reference method. The repeatability of the rapid method and the reference method in the TP measurement was also evaluated in terms of average $\% \mathrm{CV}$ and is shown in Tables 5, 6, and 7 for milk, light cream, and heavy cream, respectively. The mean $\% \mathrm{CV}$ was 0.50 and 0.55 for milk and light cream, respectively, for the rapid method. However, \%CV was relatively high for the heavy cream (1.27 and 0.76 for the rapid and reference methods, respectively). The mean absolute difference between the duplicate measurements of TP using the rapid method was $0.022 \%$, which is relatively high when compared with the $\mathrm{CP}$ measurement but is still within the AOAC requirements. It is somewhat surprising that the Sprint method provided better results for CP compared with TP because the Sprint method

Table 5. True protein (\%) of milk determined using the reference method and the rapid method along with their coefficients of variance

\begin{tabular}{|c|c|c|c|c|c|c|c|c|c|}
\hline \multirow[b]{2}{*}{ Sample no. } & \multirow[b]{2}{*}{ Fat $(\%)$} & \multicolumn{4}{|c|}{ Reference method (Kjeldahl) } & \multicolumn{4}{|c|}{ Rapid method (Sprint) } \\
\hline & & Replicate 1 & Replicate 2 & Mean & $\% \mathrm{CV}$ & Replicate 1 & Replicate 2 & Mean & $\% \mathrm{CV}$ \\
\hline 1 & 0.07 & 3.21 & 3.23 & 3.22 & 0.44 & 3.28 & 3.28 & 3.28 & 0.00 \\
\hline 2 & 0.22 & 3.20 & 3.20 & 3.20 & 0.00 & 3.24 & 3.25 & 3.25 & 0.22 \\
\hline 3 & 0.48 & 3.16 & 3.18 & 3.17 & 0.45 & 3.18 & 3.19 & 3.19 & 0.22 \\
\hline 4 & 0.72 & 3.14 & 3.17 & 3.16 & 0.67 & 3.16 & 3.17 & 3.17 & 0.22 \\
\hline 5 & 0.82 & 3.13 & 3.14 & 3.14 & 0.23 & 3.14 & 3.14 & 3.14 & 0.00 \\
\hline 6 & 1.47 & 3.12 & 3.13 & 3.13 & 0.23 & 3.13 & 3.14 & 3.14 & 0.23 \\
\hline 7 & 1.98 & 3.13 & 3.14 & 3.14 & 0.23 & 3.14 & 3.13 & 3.14 & 0.23 \\
\hline 8 & 2.47 & 3.06 & 3.08 & 3.07 & 0.46 & 3.09 & 3.09 & 3.09 & 0.00 \\
\hline 9 & 3.21 & 3.07 & 3.09 & 3.08 & 0.46 & 3.14 & 3.06 & 3.10 & 1.82 \\
\hline 10 & 3.52 & 3.02 & 3.05 & 3.04 & 0.70 & 3.08 & 3.03 & 3.06 & 1.16 \\
\hline 11 & 0.08 & 3.29 & 3.31 & 3.30 & 0.43 & 3.33 & 3.29 & 3.31 & 0.85 \\
\hline 12 & 2.03 & 3.50 & 3.51 & 3.51 & 0.20 & 3.53 & 3.50 & 3.52 & 0.60 \\
\hline 13 & 3.48 & 3.18 & 3.18 & 3.18 & 0.00 & 3.21 & 3.17 & 3.19 & 0.89 \\
\hline Average & & & & & 0.34 & & & & 0.50 \\
\hline
\end{tabular}


Table 6. True protein (\%) of light cream determined using the reference method and the rapid method along with their coefficients of variance

\begin{tabular}{|c|c|c|c|c|c|c|c|c|c|}
\hline Sample no. & Fat $(\%)$ & \multicolumn{4}{|c|}{ Reference method (Kjeldahl) } & \multicolumn{4}{|c|}{ Rapid method (Sprint) } \\
\hline 3 & 10.98 & 2.83 & 2.85 & 2.84 & 0.50 & 2.83 & 2.86 & 2.85 & 0.75 \\
\hline 4 & 11.83 & 2.82 & 2.83 & 2.83 & 0.25 & 2.80 & 2.82 & 2.81 & 0.50 \\
\hline 5 & 13.35 & 2.76 & 2.78 & 2.77 & 0.51 & 2.75 & 2.77 & 2.76 & 0.51 \\
\hline 8 & 17.01 & 2.64 & 2.66 & 2.65 & 0.53 & 2.62 & 2.61 & 2.62 & 0.27 \\
\hline 9 & 18.03 & 2.62 & 2.63 & 2.63 & 0.27 & 2.58 & 2.59 & 2.59 & 0.27 \\
\hline 10 & 18.77 & 2.57 & 2.58 & 2.58 & 0.27 & 2.54 & 2.56 & 2.55 & 0.55 \\
\hline Average & & & & & 0.33 & & & & 0.55 \\
\hline
\end{tabular}

directly measures the TP content of the sample. These results indicate that the calibration equation for $\mathrm{TP}$ could potentially be improved.

The difference plots for the measurement of the TP in milk, light cream, and heavy cream are shown in Figures 3a, b, and c. One of the 13 milks and 1 of the 10 heavy cream samples were found to be outside of the $95 \%$ confidence intervals of their mean (Figures 3a and c). The TP content of that particular milk sample measured using the reference method and rapid method was 3.22 and $3.28 \%$ (a bias of $-0.06 \%$ ), respectively. However, the TP content was $2.07 \%$ for both the reference method and the rapid method (a bias of $0 \%$ ) for the heavy cream sample, which was outside the $95 \%$ confidence intervals of the mean bias. The mean difference or the mean bias for the milk samples was $-0.018 \%$, indicating that the Sprint method produced slightly higher results when compared with the reference method. However, the mean bias was 0.005 and $0.045 \%$ for light cream and heavy cream samples, respectively (i.e., the Sprint method slightly underestimated the TP content of light and heavy cream samples). The difference plots (Figures 3a, b, and c) were also used to evaluate any relationship between the discrepancies in the reference method and the rapid method using the $\rho$. The $\rho$ between the difference of the reference and rapid method versus their mean value was found to be -0.26 , -0.77 , and -0.26 for milk, light cream, and heavy cream, respectively. The $\rho$ was found to be insignificant $(P>0.1)$ for milk and heavy cream. However, it was found to be significant $(P<0.05)$ for light cream. The bias was, however, within the $95 \%$ confidence intervals of their mean (Figure 3b).

The plots between the measured TP of milk, light cream, and heavy cream using the reference method and the rapid method are shown in Figures $4 a$, b, and c. Two samples in Figure 4a (TP contents with 3.20 and $3.22 \%$ ) seem to deviate from the regression line as well as the line of equality $(\mathrm{Y}=\mathrm{X})$. The measured TP contents of those 2 samples using the rapid method were 3.25 and $3.28 \%$, respectively. The difference plot (Figure 3a) shows that the sample with $3.2 \%$ TP (refer-

Table 7. True protein $(\%)$ of heavy cream determined using the reference method and the rapid method along with their coefficients of variance

\begin{tabular}{|c|c|c|c|c|c|c|c|c|c|}
\hline Sample no. & Fat $(\%)$ & \multicolumn{4}{|c|}{ Reference method (Kjeldahl) } & \multicolumn{4}{|c|}{ Rapid method (Sprint) } \\
\hline 1 & 30.53 & 2.12 & 2.15 & 2.14 & 0.99 & 2.10 & 2.08 & 2.09 & 0.68 \\
\hline 3 & 34.39 & 2.02 & 2.04 & 2.03 & 0.70 & 1.97 & 1.96 & 1.97 & 0.36 \\
\hline 4 & 36.56 & 1.97 & 1.98 & 1.98 & 0.36 & 1.94 & 1.88 & 1.91 & 2.22 \\
\hline 5 & 37.83 & 1.93 & 1.93 & 1.93 & 0.00 & 1.90 & 1.85 & 1.88 & 1.89 \\
\hline 8 & 41.84 & 1.77 & 1.80 & 1.79 & 1.19 & 1.81 & 1.73 & 1.77 & 3.20 \\
\hline 9 & 43.41 & 1.72 & 1.74 & 1.73 & 0.82 & 1.66 & 1.66 & 1.66 & 0.00 \\
\hline 10 & 44.78 & 1.68 & 1.70 & 1.69 & 0.84 & 1.62 & 1.64 & 1.63 & 0.87 \\
\hline Average & & & & & 0.76 & & & & 1.27 \\
\hline
\end{tabular}


(a)

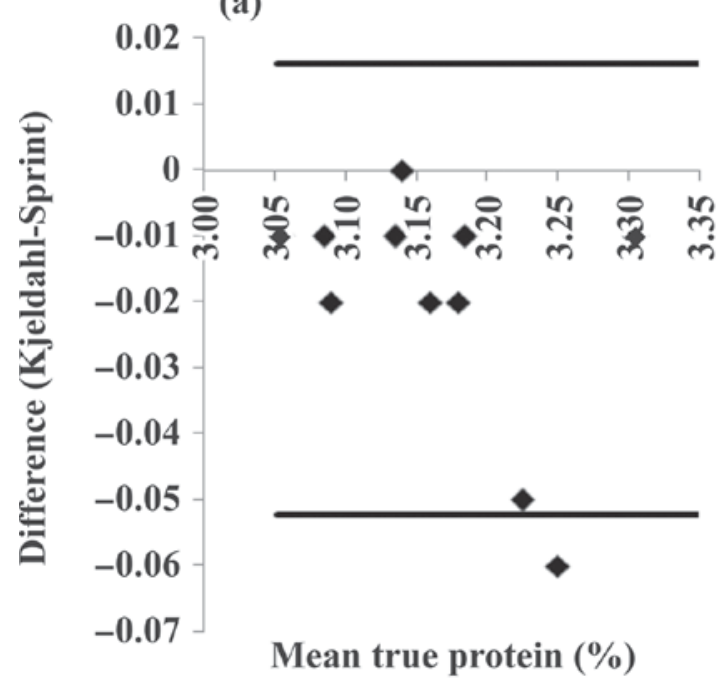

(b)

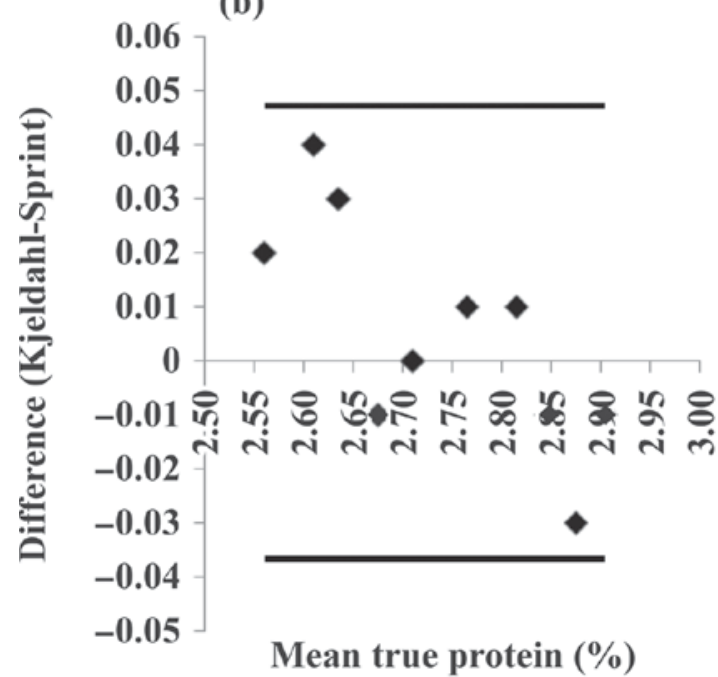

(c)

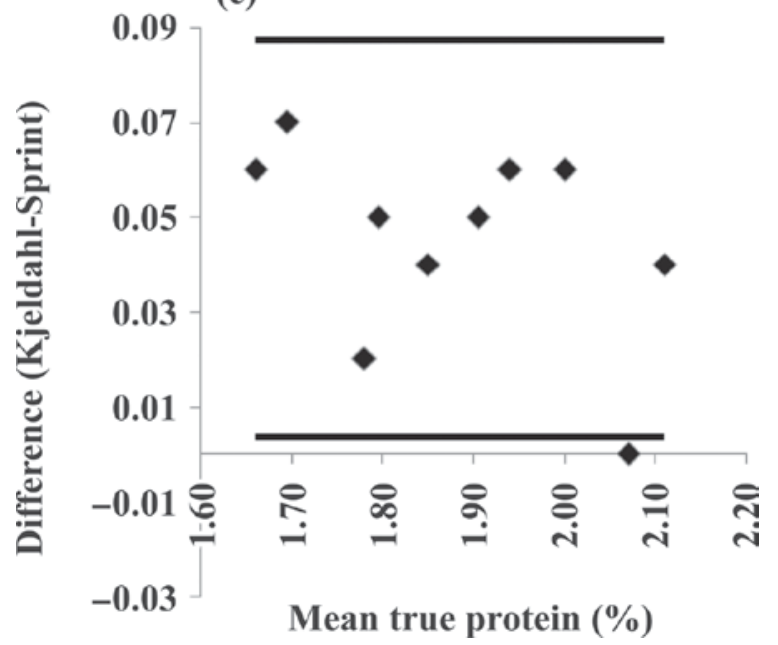

Figure 3. Plot showing the difference between the 2 methods against the mean true protein (solid line indicates mean $\pm 1.96 \mathrm{SD}$ ) for a) milk, b) light cream, and c) heavy cream.

Journal of Dairy Science Vol. 93 No. 8, 2010 (a)

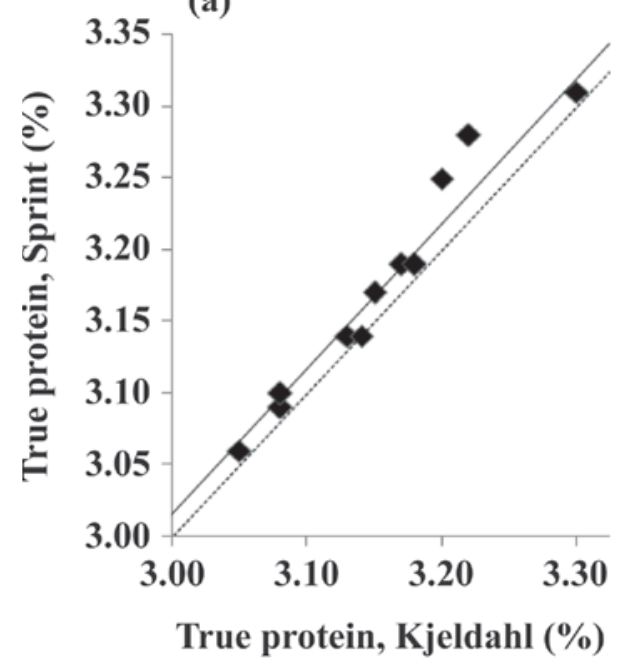

(b)

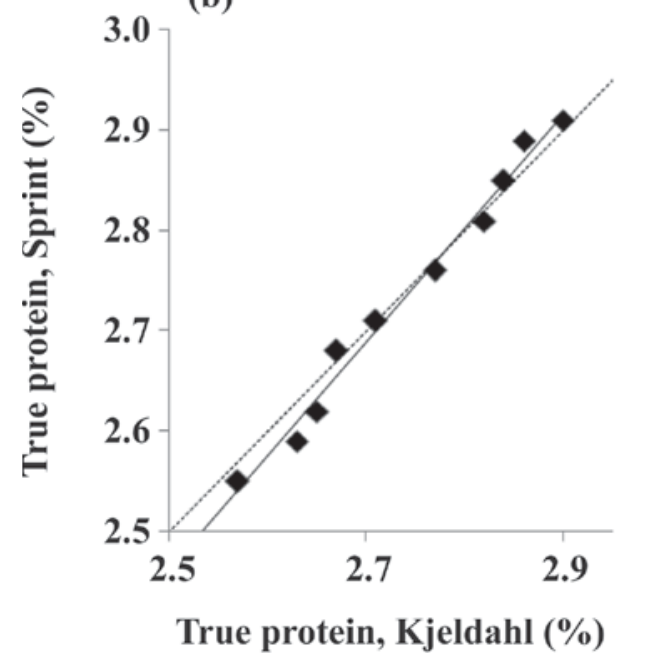

(c)

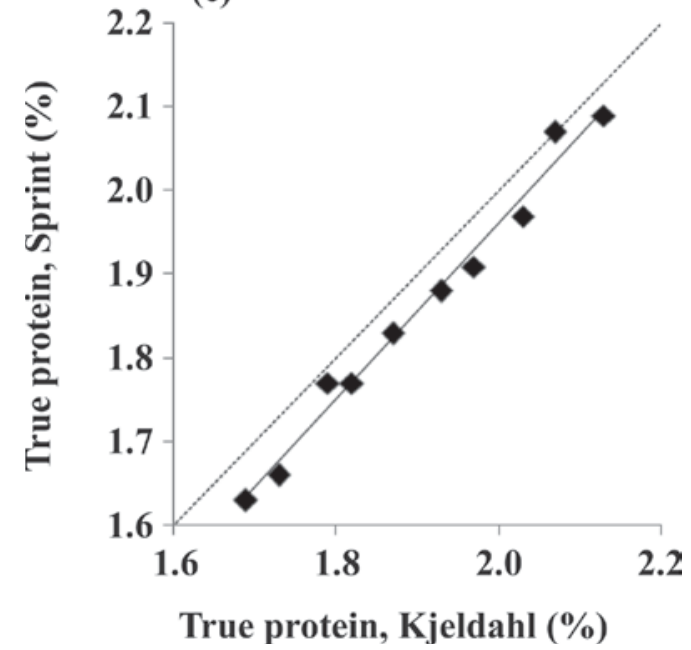

Figure 4. True protein content measured by the Kjeldahl and Sprint methods along with line of equality (dotted line; $\mathrm{Y}=\mathrm{X}$ ) for a) milk, b) light cream, and c) heavy cream. 
(a)

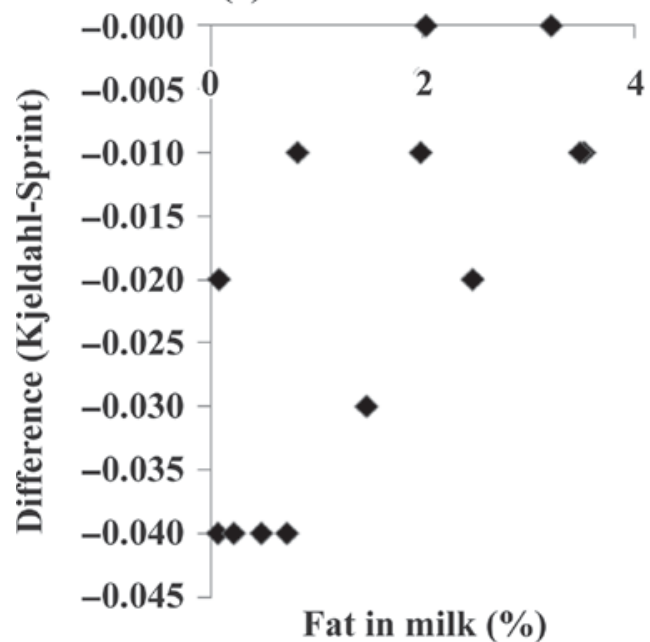

(b)

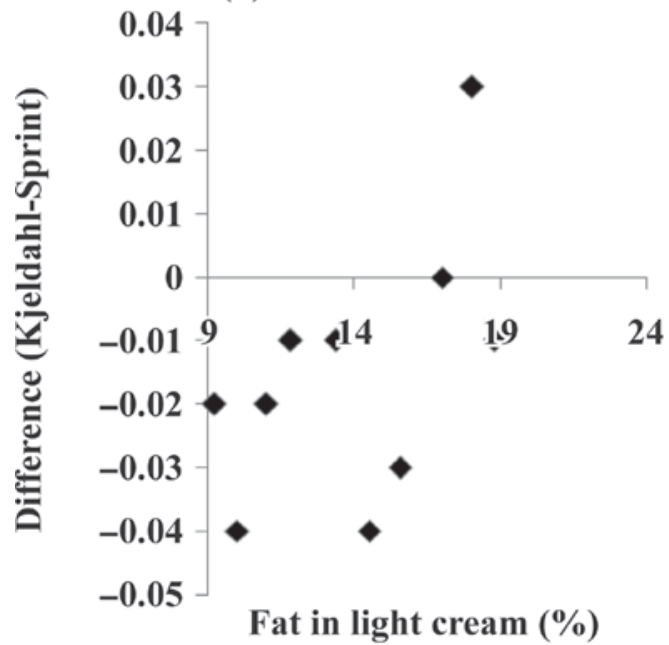

(c)

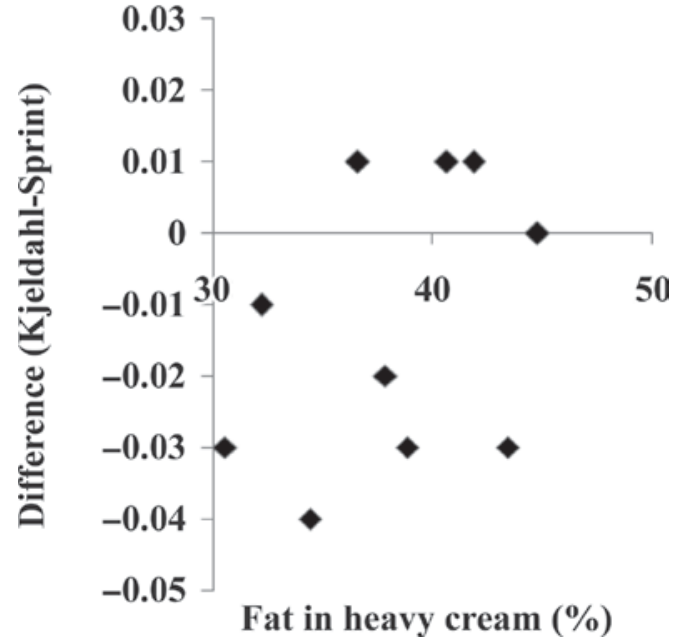

Figure 5. Visualizing the interference from fat in determination of the CP in a) milk, b) light cream, and c) heavy cream samples. (a)

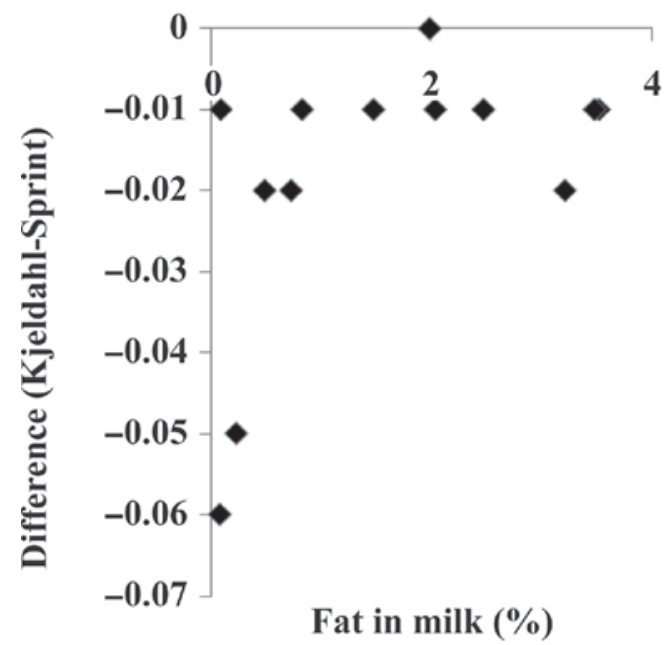

(b)

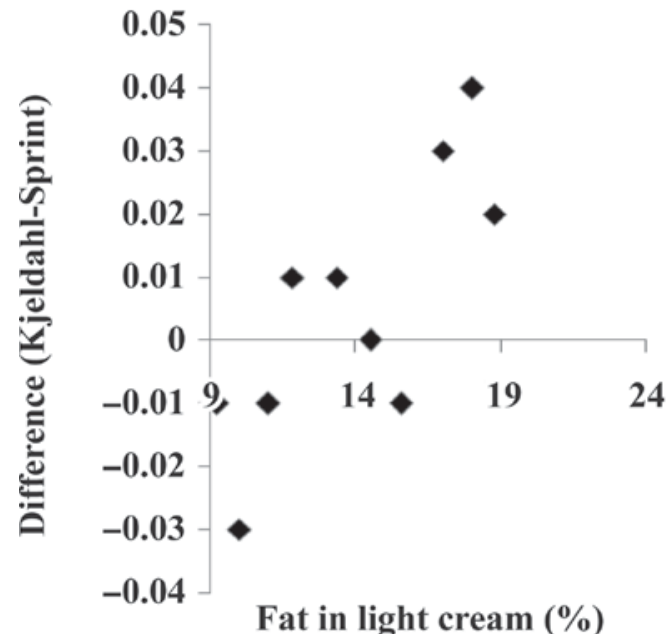

(c)

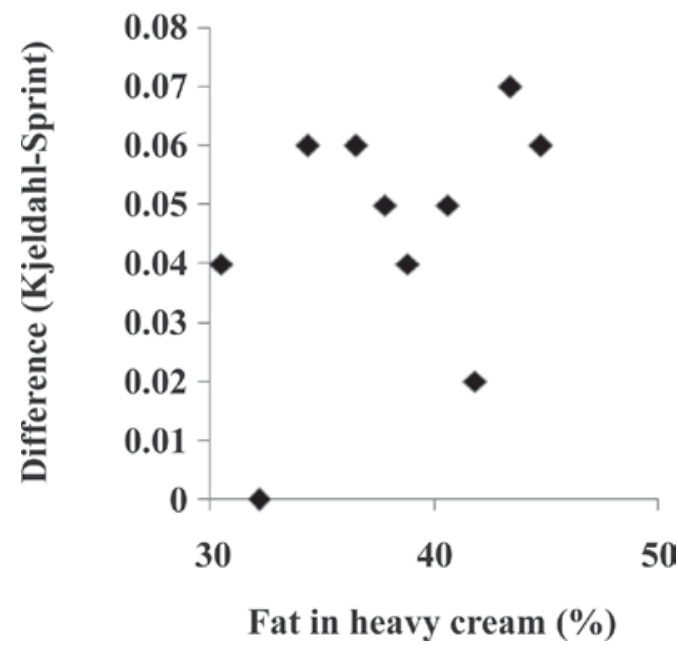

Figure 6. Visualizing the interference from fat in determination of the true protein in a) milk, b) light cream, and c) heavy cream samples. 
Table 8. Method comparison statistics for determination of true protein in the milk, light cream, and heavy cream

\begin{tabular}{|c|c|c|c|c|}
\hline Method & Parameter & Milk & Light cream & Heavy cream \\
\hline \multirow{4}{*}{ Ordinary linear regression } & Intercept & -0.015 & $-0.372^{*}$ & -0.147 \\
\hline & $\mathrm{r}^{2}$ & 0.98 & 0.99 & 0.98 \\
\hline & $95 \%$ CI for intercept & -0.321 to 0.290 & -0.674 to -0.070 & -0.354 to 0.060 \\
\hline & $\mathrm{S}_{\mathrm{y} \cdot \mathrm{x}}^{1}$ & 0.017 & 0.015 & 0.02 \\
\hline \multirow[t]{2}{*}{ Deming regression } & Slope & 1.021 & $1.143^{*}$ & 1.062 \\
\hline & 95\% CI for intercept & -0.726 to 0.629 & -0.713 to -0.080 & -0.392 to 0.064 \\
\hline
\end{tabular}

${ }^{1}$ Standard deviation of residuals.

*Statistically significant $(P<0.05)$.

ence method) was within the $95 \%$ confidence interval lines. However, the other sample with $3.22 \%$ of TP was outside of $95 \%$ confidence interval lines. The scatter plot between the reference method and the rapid method for light cream also showed a very good correlation. However, the ordinary regression line was found to be intersecting the line of equality as shown in Figure $4 \mathrm{~b}$, indicating an undermeasurement of low protein and overmeasurement of high protein contents in light cream.

The method comparison statistics for determination of TP in milk, light cream, and heavy cream are summarized in Table 8. It was observed that the slope of the regression line for milk and heavy cream samples was not significantly $(P>0.05)$ different from 1 . However, the slope of the regression line for light cream was found to be significantly $(P<0.05)$ different from 1 . This indicates that the proportional bias was significant in the case of the light cream samples. The OLR intercept followed a similar trend [significantly $(P<$ 0.05 ) different from zero for light cream]. This indicates the presence of constant bias in the TP measurement of light cream when compared with the reference method. Deming regression also provided a similar interpretation for the milk, light cream, and heavy cream. The $S_{y, x}$ calculated from the OLR line was $0.017,0.015$, and 0.02 for milk, light cream, and heavy cream, respectively. The $S_{y, x}$ represents the random error present between the 2 methods. Similar to the CP analysis, the $S_{\mathrm{y}, \mathrm{x}}$ for the TP measurement was found to be less than $0.06 \%$.

Similar to the CP measurement in milk and cream using the rapid method, the TP measurement showed a desired level of agreement with the reference method for the milk and heavy cream samples. However, light cream samples need further evaluation because of the presence of significant proportional and constant bias.

\section{Influence of Fat Content on Bias in Rapid Method}

Figures 5 and 6 show the plots between the quantitative difference between the methods (reference method
- rapid method) versus the fat content of the milk, light cream, and heavy cream during the measurement of CP and TP. On an overall basis, there was no clear influence of fat on bias (difference between the reference and rapid method). The $\rho$ was found to be 0.53 ( $P$ $>0.05)$ and $0.33(P>0.05)$ for $\mathrm{CP}$ measurement in the light cream and heavy cream, respectively. However, measurements of $\mathrm{CP}$ in milk $(\rho=0.73 ; P<0.05)$ and TP in light cream $(\rho=0.77 ; P<0.05)$ show some trend in bias relative to fat content. The bias was found to be decreasing as the fat content of milk increased. Similarly, as the fat content increased, the bias in TP measurement in light cream shifted from negative to positive. This indicates that, as the fat content increased, the rapid method underestimated the TP content in light cream. The results are also confirmed by the $\rho$ calculated between the fat content and the bias. However, Owusu-Apenten (2002) indicated that low molecular weight compounds (AA, peptides) as well as lipids do not affect protein-dye binding. On the other hand, Moran et al. (1963) stated that fat may interfere with the ability of the water-soluble dye to bind to the protein. Despite having a high percentage of fat, heavy cream samples did not show any trend between the bias and fat content for measurement of both $\mathrm{CP}(\rho$ $=0.33 ; P>0.05)$ and TP $(\rho=0.39 ; P>0.05)$. The occurrence of trend in the bias may be random and less of a concern because the bias was within the $95 \%$ confidence interval for the mean difference.

\section{CONCLUSIONS}

Protein measurement in milk, light cream, and heavy cream samples using the Sprint rapid protein analyzer was simple and rapid. No special sample preparation was required for the measurement. The $\mathrm{CP}$ and $\mathrm{TP}$ contents in milk, light cream, and heavy cream using the rapid protein analyzer showed agreement with the reference method. The regression coefficient and the intercept obtained between the reference method and 
the rapid method were not significantly different from 1 and zero for milks. The standard deviation of residuals for the rapid method was also within the acceptable limits. Overall, the Sprint rapid method has potential for routine use in measuring $\mathrm{CP}$ and $\mathrm{TP}$ in milk, light cream, and heavy cream.

\section{ACKNOWLEDGMENTS}

We thank Midwest Dairy Association (St. Paul, MN) and Dairy Management Inc. (Rosemont, IL) for their financial support, CEM Corporation (Matthews, NC) for their generous supply of consumables, and DQCI Services (Mounds View, MN) for providing the milk, light cream, and heavy cream.

\section{REFERENCES}

AOAC. 2000. Official Methods of Analysis. 17th ed. AOAC, Gaithersburg, MD.

Ashworth, U. S. 1965. Rapid method for the determination of casein in milk by the dye binding method and for the detection of mastitis. J. Dairy Sci. 48:537-540.

Ashworth, U. S. 1966. Determination of protein in dairy products by dye-binding. J. Dairy Sci. 49:133-137.

Ashworth, U. S. 1971. Proteins in meat and egg products determined by dye binding. J. Food Sci. 36:509-510.

Ashworth, U. S., R. Seals, and R. E. Erb. 1960. An improved procedure for the determination of milk proteins by dye binding. J. Dairy Sci. 43:614-623.

Barbano, D. M., J. L. Clark, C. E. Dunham, and J. R. Fleming. 1990. Kjeldahl method for determination of total nitrogen content of milk: Collaborative study. J. AOAC 73:849-859.

Barbano, D. M., and J. M. Lynch. 2006. Major advances in testing of dairy products: Milk component and dairy product attribute testing. J. Dairy Sci. 89:1189-1194.

Biston, R., and G. Clamot. 1982. Use of near-infrared reflectance spectroscopy and dye-binding techniques for estimating protein in oat groats. Cereal Chem. 59:333-335.

Bland, J. M., and D. G. Altman. 1986. Statistical methods for assessing agreement between two methods of clinical measurement. Lancet 327:307-310.

Buffler, M. 2008. A compilation of various methods for protein determination in milk, based on the classic determination by Kjeldahl. Best@buchi 49:1-4.

CEM Corporation. 2008. Sprint User Manual. CEM Corp., Matthews, NC.
Grappin, R., and B. Ribadeau-Dumas. 1992. Analytical methods for milk proteins. Pages 1-62 in Advanced Dairy Chemistry. 1: Proteins. P. F. Fox, ed., Elsevier Science Publishers, Barking, UK.

Hooi, R., D. M. Barbano, R. L. Bradley, D. Budde, M. Bulthaus, M. Chettiar, J. Lynch, and R. Reddy. 2004. Chemical and physical methods. Pages 363-536 in Standard Methods for the Examination of Dairy Products. H. M. Wehr and J. F. Frank, ed. American Public Health Association, Washington, DC

Kaldy, M. S., P. Markakis, and W. Malewski. 1972. Estimation of potato protein content by dye binding. Am. Potato J. 49:177181

Linnet, K. 1993. Evaluation of regression procedures for method comparison studies. Clin. Chem. 39:424-432.

Lynch, J. M., and D. M. Barbano. 1999. Kjeldahl nitrogen analysis as a reference method for protein determination in dairy products. J. AOAC Int. 82:1389-1398.

Martin, R. F. 2000. General Deming regression for estimating systematic bias and its confidence interval in method-comparison studies. Clin. Chem. 46:100-104.

Moran, E. T. Jr., L. S. Jenson, and J. McGinnis. 1963. Dye binding by soybean and fish meal as an index of quality. J. Nutr. 79:239244.

O'Sullivan, A., B. O'Connor, A. Kelly, and M. J. McGrath. 1999. The use of chemical and infrared methods for analysis of milk and dairy products. Int. J. Dairy Technol. 52:139-148.

Owusu-Apenten, R. K. 2002. Food Protein Analysis: Quantitative Effects on Processing. CRC Press, New York, NY.

Posudin, Y. I. 2007. Practical Spectroscopy in Agriculture and Food Science. Science Publishers, Enfield, NH.

Riquelme, E., and U. S. Ashworth. 1973. Determination of protein content of lamb meat by dye binding. J. Anim. Sci. 36:11971198.

Sherbon, J. W. 1978. Recent developments in determining protein content of dairy products by dye binding. J. Dairy Sci. 61:12741278 .

Simonne, A. H., E. H. Simonne, R. R. Eitenmiller, H. A. Mills, and C. P. Cresman III.. 1997. Could the Dumas method replace the Kjeldahl digestion for nitrogen and crude protein determinations in foods? J. Sci. Food Agric. 73:39-45.

Twomey, P. J. 2006. How to use difference plots in quantitative method comparison studies. Ann. Clin. Biochem. 43:124-129.

Van Reusel, A., and C. J. Klijn. 1987. Dye binding method for determination of protein in milk. Pages 17-20 in Monograph on Rapid Indirect Methods for Measurement of the Major Components of Milk. Bulletin no. 208. International Dairy Federation, Brussels, Belgium.

Wiles, P. G., I. K. Gray, and R. C. Kissling. 1998. Routine analysis of proteins by Kjeldahl and Dumas methods: Review and interlaboratory study using dairy products. J. AOAC Int. 81:620632

Wu, W. B., and A. L. Lakin. 1993. Estimation of protein in potato tissue by dye binding. Food Chem. 46:49-53. 